\title{
Association Between Self-Care Behaviors and Quality of Life Among Elderly Minority Groups on the Border of Thailand
}

This article was published in the following Dove Press journal: Journal of Multidisciplinary Healthcare

\author{
Parichat Ong-artborirak' \\ Katekaew Seangpraw (iD ${ }^{2}$ \\ 'Faculty of Public Health, Chiang Mai \\ University, Chiang Mai 50200, Thailand; \\ ${ }^{2}$ School of Medicine (Public Health), \\ University of Phayao, Phayao 56000, \\ Thailand
}

Introduction: Quality of life among the elderly is an important public health issue. However, few studies have examined the health and quality of life among ethnic minority groups. This research aimed to study the association between self-care behaviors and quality of life among the elderly from ethic minority groups living along the borders of Thailand.

Methods: Three provinces from the northern part of Thailand, including Tak, Nan, and Phayao, were selected for the area of study. The purposive method was employed to select districts within the province. Simple random sampling was used to select samples. A total number of 810 elderly citizens were recruited from ethnic minority groups as a research sample. The assessment questionnaire WHOQOL-OLD was used for interviewing the elderly. Results: The mean age of the elderly in our sample was 68.3 years, representing ethnic groups of Lua (30.9\%), Karens (24.6\%), Tai Lue (23.3\%), and Tai Hmong (21.2\%). The level of selfcare behaviors of these elderly was moderate (49.5\%), low (45.9\%), and high (4.6\%). More than half of them exhibited the quality of life at a moderate level $(69.1 \%)$ and low level (26.5\%); only a few demonstrated a high level (4.4\%). Linear regression analysis revealed that self-care behaviors were positively significantly related to the quality of life among ethnic groups ( $\mathrm{p}$-value $<0.001$ ). Other variables such as age, ethnic group, education, incurrent disease, and smoking were associated with quality of life among the elderly ( $p$-value $<0.05$ ).

Conclusion: Health promotion to improve health and self-care behaviors among the elderly living along the borders of Thailand should be encouraged through the culture, tradition, and beliefs of particular ethnic groups. Proactive health services and health awareness should be promoted by health agencies and related organizations in order to improve the health, wellbeing, and quality of life among the elderly people from ethnic minority groups.

Keywords: self-care behavior, quality of life, elderly minority

\section{Introduction}

The number of those in the aging population is increasing rapidly worldwide. According to the United Nations, it is estimated that there are currently 350 million elderly globally, and this figure is expected to reach one billion by 2025 . The numbers of elderly people are increasing, especially in developing countries. ${ }^{1}$ In Thailand, there were approximately 11 million elderly people (16.5\%) aged 60 years and older in 2018 , and this number is expected to increase 5 percent every year. ${ }^{2}$ Thailand houses people of various nationalities, cultures, and languages; moreover, there are more than 70 ethnic minority groups living in the country. ${ }^{3}$ Ethnic groups inherit cultures, traditions, and languages from their ancestors from generation to generation,
Correspondence: Katekaew Seangpraw School of Medicine, University of Phayao, Thailand

Email eungkaew@gmail.com 
bringing them aspects of a unique identity. ${ }^{4}$ Ethnic groups can be classified according to the characteristics of their settlements, as described in four ways: (1) Settlers living in mountainous or highland areas called hill tribes, (2) Settlers living in plateau areas, (3) Settlers living along the coastal or sea areas called Chao Le, and (4) Settlers living in forest areas. ${ }^{3,5}$ Due to changes in the overall population structure of the elderly, it is predicted that the number of elderly from ethnic minority groups will increase continuously. In addition, these elderly people will be affected by the changes in population structure in terms of family, society, economy, and environment. ${ }^{6}$ Literature reviews of elderly and ethnic group studies reveal that many of the elderly people from ethnic minority groups are working in the agricultural sector, which provides less income than other industries; moreover, they have little educational background, resulting in a lack of knowledge and preparation of an aging society.,

Due to the aging process, elderly people will face changes in physical and mental health that can impact their daily activity, social participation, and household economy. ${ }^{6}$ In some situations, if these elderly people cannot adjust to life changes or are not able to take care of themselves, they can become a burden to their family or a society. ${ }^{3,5,6}$ During the aging process, many elders may face reduced physical and mental functions. ${ }^{6}$ Moreover, many elderly people are more likely to develop chronic diseases as their age progresses. ${ }^{5,6}$

Information from the Bureau of Non-Communicable Diseases (2018) indicates that the most common chronic conditions found among elderly people are hypertension, diabetes, and osteoarthritis, accounting for $41.1 \%, 18.2 \%$, and $8.6 \%$, respectively. ${ }^{7}$ The severity of the diseases rises as age increases, thus affecting the mind and the body of the elderly. When they experience reduced ability to perform daily activities, they can also experience anxiety, fear, and stress. Aging individuals may feel that they are a burden on family members, they may experience less interaction with society, and they may not be able to earn an income as before. If this feeling continues over time, they can develop low self-worth, experience depression, and live an unhappy life. These changes in the physical, mental, and social conditions will cause a huge impact on the quality of life among elderly people. ${ }^{8}$

Quality of life is a perception people experience through culture and situations. It is found to be related to expectation and awareness in each person. Quality of life consists of four domains: physical, psychological, social relationships, and environment. These factors are interrelated. ${ }^{9}$ Self-care behaviors represent one important aspect of a healthy lifestyle. People with a high degree of self-care behaviors pay attention to their health care, and if they do require medical attention, they seek to regain their health as soon as possible. ${ }^{8,10}$ Self-care behaviors improve quality of life and reduce health care costs. ${ }^{3,8}$ Literature reviews reveal that there is limited research focusing on the associated relationship between self-care behaviors and quality of life of the elderly from ethnic minority groups due to access restrictions, inconvenient transportation, language communication, and sensitivity among the ethnic groups. Therefore, the current study focuses on the relationship between self-care behaviors and the quality of life of the elderly from ethnic minority groups living along the northern borders of Thailand. The researcher adopted the concept of self-care; ${ }^{10}$ he believes that, if a person demonstrates proper self-care behaviors, his or her quality of life will be improved. Furthermore, the quality of life assessment questionnaire WHOQOL-OLD ${ }^{11}$ will be used to assess the well-being of the elderly in the study, which includes six elements: sensory abilities, autonomy, past-present-future activities, social participation, death and dying, and intimacy. ${ }^{11,12}$ It is believed that such elements reflect the living conditions and quality of life of the elderly; moreover, the obtained information can help shape a health promotion plan that is suitable for the societies, cultures, traditions, and beliefs among the elderly in ethnic minority groups.

\section{Methodology}

This analysis was a cross-sectional study. The quantitative data collection was performed in rural areas or northern border provinces of Thailand, including Tak, Nan, and Phayao. These border provinces are important areas that connect Thailand with Burma and Laos. The geographical characteristics of the borders are high mountains with a large forest area. The data collection was conducted from October 2018 to February 2019. The population is large, and the researcher did not have access to the exact population due to the migration of ethnic minority people; however, the sample size could be calculated from the formula without knowledge of the exact sample size applied from Cochran. ${ }^{13}$ The formula ${ }^{14}$ is $\mathrm{n} / \mathrm{k} \geq 30$ in which:

$\mathrm{n}=$ the number of sample used in research per 1 variable

$\mathrm{k}=$ the number of independent variables, which is 9 ; the formula of the sample size calculation is $n=30 \times 9=270$. 
Therefore, the total samples used in the research from 3 provinces were 810 persons; 270 persons were selected per province.

The purposive sampling was employed within the study in the following order (1). The province that has a large number of ethnic populations was selected for the study, including the ethnic groups of Karen and Lua from the highlands or hill tribes and the Tai Lue and Tai Hmong from the flat plateau areas (2). Area cluster sampling was done by dividing the administrative district in each province, and then the district with the most elderly people from ethnic minorities, more than $50 \%$, was selected. After that, simple random sampling was performed by drawing the district out of each province. From the total 9 districts from the Phayao province, Chiang Kam district was selected; from 15 districts in the Nan province, Boa Kluae was selected; and from the 9 districts in Tak province, Ta Yang district was selected. The inclusion criteria were (a) both male or female aged 60 years and older; (b) belonging to an ethnic group registered with the Health Center of Ethnic group, Department of Health, Ministry of Public Health; (c) residence in the area of more than 2 years; (d) no history of diagnosis as a psychiatric patient; and (f) willingness to participate and sign the consent form before participating in the study. Persons with cognitive impairment were excluded.

The process of conducting the research is described as follows: The researcher recruited 15 local assistant researchers per province with the qualifications of the ability to communicate with the elderly from ethnic minority groups using local language. The majority of the assistant researchers were recruited from the village, and most were village health volunteers. They had to be qualified before helping to conduct the study. One day of research process training was performed to enable every assistant researcher to understand the process and perform the study with the same objective and direction. The training included the purpose of the study, data collection, assessment technique, time interview, appointment, and understanding of the human rights protection for the participants. The researcher converted the official language into the local language so that communication would be easier and more suitable for the community context of ethnic minority groups. After that, the assistant researcher converted the local language into the spoken language of each ethnic group, performed without using written language. The process of data collection was first done by the research coordinated with each provincial health office before entering the research area. Then, door-to-door home interviews with the elderly were conducted. The assistant researcher helped the researcher interview participants; the interviews lasted $30-45$ mins per person. Ethical consideration was approved by the University of Phayao Human Ethnic Committee: UP-HEC (ID=3/023/ 60). Participants were informed about the aims, procedures, and benefits of the study. Participation was fully voluntary, and informed written consent was obtained. This study was conducted in accordance with the Declaration of Helsinki.

A questionnaire that included three parts was used to interview elderly participants. Part one consists of information on general characteristics, including gender, age, marital status, income, education, ethnic group, health history, and alcohol and cigarette consumption. Part two consisted of a self-care behaviors assessment questionnaire (Appendix 1), developed from the Orem Theory for the suitability of the community context of ethnic groups and previous research. ${ }^{10,15,16}$ There are three sections of the questionnaire: (1) Universal self-care requisites such as food and water consumption, adequate air, excretion, waste drainage, activity and relaxation, personal time and social interaction, prevention of health hazards, and health promotion and development. Examples of questions are, "Do you avoid drinking sweetened beverages such as smoothies, soft drinks, and various sugary drinks?"; "Do you regularly participate in community activities such as visiting temple or attending religious ceremonies?"; or "Do you wash your hands with soap every time after using toilet or excretion?" (2) Development self-care requisites consisted of activities that promote the emotional and mental development of the elderly, such as praying or engaging in meditation. An example of the questions was, "When you experience sadness or stress, how do you manage your emotions?" and (3) Health deviation self-care requisites consisted of activities for self-care behaviors according to their physical structures or health functions. An example of the questions was "When illness occurs, will you seek help from a doctor, nurse, or health officers at the local health center near your house?" The questions included 63 items in total, using a rating scale to evaluate the score. The scale consisted of four levels: Never practice at all, Practice once in a while, Practice sometimes, and Practice regularly. Possible scores ranged from 63 to 252 points. The scores were divided into three levels: High level $=$ more than or equal to $80 \%$ (score $\geq 201$ ), Moderate level $=$ between $60 \%$ and $79 \%$ 
(score range from 152 to 200), and Low level = less than $60 \%$ (score $\leq 151$ ). The content validity of questionnaires was examined by three experts in health behaviors, elderly health, and public health, and the Cronbach's alpha coefficient for reliability assessment was 0.83. Part three included the quality-of-life assessment questionnaire (WHOQOL-OLD) applied from the World Health Organization for elderly people, which was translated into the Thai language by Somrongthong et al. ${ }^{12,17}$ The questionnaire consisted of 24 items in 6 domains, including (1) Sensory functioning $(\mathrm{SAB})=4$ items, (2) Autonomy (AUT) $=4$ items, (3) Past present and future activities $(\mathrm{PPF})=4$ items, (4) Social participation $(\mathrm{SOP})=$ 4 items, (5) Death and dying (DAD) $=4$ items, and (6) Intimacy $(\mathrm{INT})=4$ items. The questionnaire used a rating scale ranging from 1 (not at all) to 5 (an extreme amount). Possible scores in each domain ranged from 4 to 20 points. The score is totaled at three levels: a score of $24-55$ equals a low quality of life, 56-88 equals a moderate quality of life, and 89-120 equals a high quality of life. The reliability of the questionnaire analyzed using Cronbach's alpha coefficient was 0.88 .

\section{Data Analysis}

Statistical analysis was performed using the SPSS software version 20, licensed from the University of Phayao (SPSS Inc., Chicago, IL, USA). Statistical analysis including frequency, percentage, mean, and standard deviation (SD) was used to analyze the general characteristics information. The factors and self-care behaviors associated with quality of life were determined by linear regression. A bivariate analysis was done, and then variables with $\mathrm{p}$-value $<0.15$ were included in the multivariate analysis. The variables which were statistically significant at the 0.05 level were put into the final model using the enter method.

\section{Results}

A total of 810 elderly from ethnic minority groups participated in the study. The ethnic minority groups from the highland were Lua (30.9\%) and Karens (24.6\%) and from the plateau were Tai Lue (23.3\%) and Tai Hmong (21.2\%). General characteristics information is summarized in Table 1.

The self-care behaviors and quality of life among the elderly from ethnic minority groups are shown in Table 2. The highest mean scores of self-care behaviors were found in the ethnic groups of Tai Lue, Tai Hmong, Lua, and Karens. In terms of quality of life, the ethnic group of
Lua was found to have the highest mean score, followed by Tai Lue, Karens, and Tai Hmong. Interestingly, the mean score for quality of life for the domain of DAD in the Lua group was found to be lower than in other ethnic groups, whereas the domains of SAB, AUT, PPF, SOP, and INT were highest.

\section{Relationship Between Self-Care Behaviors and Quality of Life}

Linear regression analysis was used to identify self-care behaviors and other variables that were associated with quality of life. In the bivariate analysis, six variables were statistically significantly associated with quality of life at p-value $<0.15$ (Table 3). All six variables were entered into the multivariate regression model, and drinking alcohol became a non-significant factor. In the last multivariate model, the results showed that five variables - age, ethnic, incurrent disease, smoking, and self-care behaviors - were significantly related to the quality of life $(\mathrm{p}<0.05)$ (Table 4$)$. There was an inversely significant relationship between age and score of quality of life (beta $=-0.402$, p-value $<0.001$ ). The score of quality of life was significantly higher in Lua and Karens than in Tai Hmong (p-value $<0.001$ ). The score of quality of life was lower among people who had diseases than those who did not. The model predicted that quality of life was 2.59 points lower in smokers than non-smokers (p-value $<0.001)$. Moreover, increasing each score for selfcare behaviors could increase the quality of life by about 0.30 points (beta $=0.474$, $\mathrm{p}$-value $<0.001$ ).

When classified by ethnic group, the multivariate analysis revealed that age, having diseases, and self-care behaviors were significantly associated with quality of life among the ethnic groups of Lua, Karens, and Tai Hmong, as shown in Table 5. In the ethnic group of Tai Lue, not only age, having diseases, and self-care behaviors but also smoking were significantly associated with quality of life. In addition, the standardized coefficients between the score of self-care behaviors and the score of quality of life were found to be highest in the ethnic group of Tai Lue (0.510), followed by Lua (0.499), Karens (0.474), and Tai Hmong (0.438).

\section{Discussion}

This study shows that elderly people's self-care behavior performance was at a moderate level. When considering personal factors, the elderly participants demonstrated a reported mean age of 68.3 years old. It can be explained 
Table I Socio-Demographic of Elderly Minority Groups in Border of Thailand $(\mathrm{N}=8 \mid 0)$

\begin{tabular}{|c|c|c|c|c|c|}
\hline Variable & Total N(\%) & Lua n(\%) & Karens n(\%) & Tai Lue n(\%) & Tai Hmong n(\%) \\
\hline \multicolumn{6}{|l|}{ Age, years } \\
\hline $60-69$ & $5 I I(63.0)$ & $153(61.2)$ & $134(67.4)$ & $114(60.3)$ & $110(64.0)$ \\
\hline $70-79$ & $243(30.0)$ & $78(31.2)$ & $5 I(25.6)$ & $67(35.4)$ & $47(27.3)$ \\
\hline$\geq 80$ & $56(7.0)$ & $19(7.6)$ & $14(7.0)$ & $8(4.3)$ & $15(8.7)$ \\
\hline \multicolumn{6}{|l|}{ Mean $(S D)=68.3(7.1)$, Min $-\operatorname{Max}=60-89$} \\
\hline \multicolumn{6}{|l|}{ Gender } \\
\hline Male & $310(38.3)$ & $83(33.2)$ & $75(37.7)$ & $89(47.1)$ & $63(36.6)$ \\
\hline Female & $500(61.7)$ & $167(66.8)$ & $124(62.3)$ & $100(52.9)$ & $109(63.4)$ \\
\hline \multicolumn{6}{|l|}{ Marital status } \\
\hline Single (divorced/separated) & $387(47.8)$ & $125(50.0)$ & $94(47.2)$ & $81(42.9)$ & $87(50.6)$ \\
\hline Marriage & $423(52.2)$ & $125(50.0)$ & $105(52.8)$ & $108(57.1)$ & $85(49.4)$ \\
\hline \multicolumn{6}{|l|}{ Education } \\
\hline No education & $531(65.6)$ & I79(7I.6) & $107(53.8)$ & $|3|(69.3)$ & $114(66.3)$ \\
\hline Primary school & $279(34.4)$ & 7I(28.4) & $92(46.2)$ & $58(30.7)$ & $58(33.7)$ \\
\hline \multicolumn{6}{|l|}{ Incomes (Baht/month) } \\
\hline $600-999(\$ 19-31)$ & $309(38.1)$ & 146(58.4) & $61(30.7)$ & $57(30.1)$ & $45(26.2)$ \\
\hline $1000-4999(\$ 32-159)$ & $383(47.3)$ & $93(37.2)$ & $98(49.2)$ & $98(51.9)$ & $94(54.7)$ \\
\hline$\geq 5000(\$ 160)$ & $118(14.6)$ & II (4.4) & $40(20.1)$ & $34(18.0)$ & $33(19.1)$ \\
\hline \multicolumn{6}{|l|}{ Mean $(S D)=2124.4(2630.8)$, Min $-\operatorname{Max}=600-15,700$} \\
\hline \multicolumn{6}{|l|}{ Financial status } \\
\hline Insufficient & $753(93.0)$ & $245(98.0)$ & $180(90.5)$ & $170(89.9)$ & 158(91.9) \\
\hline Sufficient & $57(7.0)$ & $5(2.0)$ & $19(9.5)$ & $19(10.1)$ & $14(8.1)$ \\
\hline \multicolumn{6}{|l|}{ Incurrent disease/Medical history } \\
\hline No & $380(46.9)$ & $115(46.0)$ & $78(39.2)$ & $92(48.7)$ & $95(55.2)$ \\
\hline Yes & $430(53.1)$ & $135(54.0)$ & $121(60.8)$ & $97(51.3)$ & $77(44.8)$ \\
\hline Hypertension (HT) & $205(47.6)$ & $55(40.7)$ & $40(33.0)$ & $56(57.8)$ & $54(70.1)$ \\
\hline Diabetes mellitus (DM) & $135(31.3)$ & $49(36.0)$ & $48(39.6)$ & $25(25.9)$ & $13(17.0)$ \\
\hline Stress & $19(4.4)$ & $\mathrm{I}(\mathrm{I} .0)$ & $12(10.0)$ & $5(5.1)$ & $\mathrm{I}(\mathrm{I} .2)$ \\
\hline Stroke & $17(4.0)$ & $5(3.0)$ & $7(5.7)$ & $4(4.1)$ & $\mathrm{I}(\mathrm{I} .2)$ \\
\hline Coronary heart disease (CHD) & $26(6.0)$ & $9(6.0)$ & $8(6.7)$ & $4(4.1)$ & $5(6.8)$ \\
\hline Tuberculosis & $12(3.0)$ & $\mathrm{II}(10.3)$ & $0(0.0)$ & $0(0.0)$ & $\mathrm{I}(\mathrm{I} .2)$ \\
\hline Chronic obstructive pulmonary disease (COPD) & 16(3.7) & $5(3.0)$ & $6(5.0)$ & $3(3.0)$ & $2(2.5)$ \\
\hline \multicolumn{6}{|l|}{ Alcohol intake } \\
\hline No & $324(40.0)$ & $102(40.8)$ & $88(44.2)$ & $70(37.0)$ & $64(37.2)$ \\
\hline Yes & $486(60.0)$ & | 48(59.2) & III(55.8) & $119(63.0)$ & $108(62.8)$ \\
\hline \multicolumn{6}{|l|}{ Smoking } \\
\hline No & $546(67.4)$ & $173(69.2)$ & $116(58.3)$ & $129(68.3)$ & $128(74.4)$ \\
\hline Yes & $264(32.6)$ & $77(30.8)$ & $83(4 \mid .7)$ & $60(31.7)$ & $44(25.6)$ \\
\hline
\end{tabular}

that they are getting older and their self-care performance reduces as age progresses. As expected, the study found that, as people age, their self-care behaviors related to health are reduced. ${ }^{18}$ The study reported that these elderly people did not have education, which is associated with health self-care skills. Consistent with previous research, there were relationships between education and health care knowledge and self-care behaviors; one study mentioned that having less knowledge can result in increased morbidity among the elderly. ${ }^{19}$

This study focused on self-care behaviors among ethnic minority groups. It is important for the researcher to 
Table 2 Descriptive Analysis of Self-Care Behavior and Quality of Life Among Elderly Minority Groups (N=810)

\begin{tabular}{|c|c|c|c|c|c|}
\hline Variable & Total N(\%) & Lua n(\%) & Karens n(\%) & Tai Lue n(\%) & Tai Hmong n(\%) \\
\hline \multicolumn{6}{|l|}{ Self-care behaviors } \\
\hline Low level $(\leq 15 \mid)$ & $372(45.9)$ & $119(47.6)$ & $116(58.3)$ & $66(35.0)$ & $7 \mid(4 I .3)$ \\
\hline Moderate level (152-200) & $40 \mathrm{I}(49.5)$ & $119(47.6)$ & $75(37.7)$ & III(58.7) & $96(55.8)$ \\
\hline High level $(\geq 20 \mathrm{I})$ & $37(4.6)$ & $12(4.8)$ & $8(4.0)$ & $12(6.3)$ & $5(2.9)$ \\
\hline Mean (SD) & $150.4(19.2)$ & $150.1(\mid 8.8)$ & $145.7(19.1)$ & $153.8(20.4)$ & $152.3(17.5)$ \\
\hline Min - Max & $103-213$ & $110-208$ & $|I|-2 \mid 3$ & $103-206$ & $114-210$ \\
\hline \multicolumn{6}{|l|}{ Total Quality of Life (TQOL) } \\
\hline Low level $(\leq 55)$ & $215(26.5)$ & $74(29.6)$ & $39(19.6)$ & $5 I(27.0)$ & $5 I(29.7)$ \\
\hline Moderate level (56-88) & $560(69.1)$ & $161(64.4)$ & $152(76.4)$ & $130(68.8)$ & $117(68.0)$ \\
\hline High level $(\geq 89)$ & $35(4.4)$ & $15(6.0)$ & $8(4.0)$ & $8(4.2)$ & $4(2.3)$ \\
\hline Mean (SD) & $63.0(12.1)$ & $64.7(13.7)$ & $62.0(10.2)$ & $63.2(12.1)$ & $61.2(11.2)$ \\
\hline Min - Max & $40-106$ & $4 \mid-98$ & $4 \mid-98$ & $4 I-104$ & $40-106$ \\
\hline \multicolumn{6}{|l|}{ Domain I: Sensory functioning (SAB) } \\
\hline Mean (SD) & $10.3(2.3)$ & $10.7(2.5)$ & $9.9(2.0)$ & $10.2(2.3)$ & $10.0(2.1)$ \\
\hline Min - Max & $5-19$ & $6-19$ & $5-17$ & $6-18$ & $6-16$ \\
\hline \multicolumn{6}{|l|}{ Domain 2: Autonomy (AUT) } \\
\hline Mean (SD) & $9.6(2.8)$ & $10.5(3.2)$ & $8.9(2.1)$ & $9.4(2.8)$ & $9.2(2.7)$ \\
\hline Min - Max & $5-20$ & $5-9$ & $8-18$ & $6-18$ & $5-20$ \\
\hline \multicolumn{6}{|l|}{ Domain 3: Past present and future activities (PPF) } \\
\hline Mean (SD) & $10.9(2.7)$ & $11.8(3.2)$ & $10.4(2.1)$ & $10.9(2.6)$ & $10.5(2.5)$ \\
\hline Min - Max & $6-20$ & $6-20$ & $7-19$ & $6-20$ & $6-20$ \\
\hline \multicolumn{6}{|l|}{ Domain 4: Social participation (SOP) } \\
\hline Mean (SD) & $10.4(3.0)$ & $11.6(3.5)$ & $9.7(2.3)$ & $10.1(2.8)$ & $9.9(2.8)$ \\
\hline Min - Max & $5-20$ & $6-20$ & $6-16$ & $5-20$ & $5-20$ \\
\hline \multicolumn{6}{|l|}{ Domain 5: Death and dying (DAD) } \\
\hline Mean (SD) & $10.0(3.3)$ & $7.9(3.0)$ & $11.6(2.6)$ & $10.8(3.0)$ & $10.1(3.1)$ \\
\hline Min - Max & $4-19$ & $4-18$ & $6-18$ & $4-17$ & $4-19$ \\
\hline \multicolumn{6}{|l|}{ Domain 6: Intimacy (INT) } \\
\hline Mean (SD) & II.5(2.5) & $12.1(3.2)$ & II.I(I.8) & II.4(2.3) & II.I(2.I) \\
\hline Min - Max & $7-20$ & $7-20$ & $8-19$ & $7-20$ & $7-20$ \\
\hline
\end{tabular}

understand the different health practices among groups of people. A previous study reported that some elders perform self-care based on their beliefs, traditions, cultures, and lifestyle practices. ${ }^{20}$

To understand the participants' cultures, beliefs, and practices, the researcher reviewed several studies regarding ethnic group studies. It is reported that the ethnic group of Tai Lue believes that an illness is caused by many reasons, one of which is superstitious. When illness occurs among members of the group, at first they will buy medicine from a local drugstore for initial treatment. However, if the illness becomes more severe, they will seek health treatment from a traditional healer, use herbal medicine in the treatment, and perform a mouth-blowing ritual. ${ }^{21}$ The Lua have the belief in spiritual healing called a spirit butterfly house, in which the traditional healer ties a white thread around the wrist of the patient, performs a ritual using herbal medicine, and performs mouth blowing into the body of a patient. ${ }^{5,21}$ The Karens believe in nature spirits or superstitious. They worship these spirits by killing chicken served with brewed alcohol. This is how the tribe heal illness occurred to the group members. They believe that this will bring happiness to the family and society. The Tai Hmong believe that sacred things are in nature, such as the sky, rivers, the wind, or mountains. They inherited this belief from their ancestor's generation by generation. Similarly, to the Karens, they worship the sacred with fresh meat and alcohol, and then they provide the worshiped food to the ill person. ${ }^{21}$ These people 
Table 3 Relationship Between Predictors and Quality of Life Among Elderly Minority Groups, Bivariate Analysis by Linear Regression

\begin{tabular}{|l|l|l|l|l|}
\hline Variables & B & SE & Beta & p-value \\
\hline Age (years) & -0.762 & 0.054 & -0.444 & $<0.00 I^{*}$ \\
Gender & -0.602 & 0.878 & -0.024 & 0.493 \\
Education & 0.554 & 0.898 & 0.022 & 0.538 \\
Marital status & 1.182 & 0.854 & 0.049 & 0.166 \\
Income & -0.583 & 0.621 & -0.033 & 0.349 \\
\hline Ethnic & & & & \\
$\quad$ Tai Hmong & Ref. & & & \\
$\quad$ Lua & 3.551 & 1.197 & 0.135 & $0.003^{*}$ \\
$\quad$ Karens & 0.829 & 1.258 & 0.029 & 0.510 \\
$\quad$ Tai Lue & 2.065 & 1.274 & 0.072 & 0.105 \\
\hline Incurrent disease & & & & \\
No & Ref. & & & \\
HT & -4.689 & 1.024 & -0.168 & $<0.00 I^{*}$ \\
DM & -6.256 & 1.184 & -0.192 & $<0.00 I^{*}$ \\
Other diseases & -6.748 & 1.385 & -0.175 & $<0.00 I^{*}$ \\
\hline Alcohol intake & -2.573 & 0.867 & -0.104 & $0.003^{*}$ \\
Smoking & -3.611 & 0.902 & -0.139 & $<0.00 I^{*}$ \\
Self-care behaviors (scores) & 0.327 & 0.019 & 0.517 & $<0.00 I^{*}$ \\
\hline
\end{tabular}

Notes: Variables: gender (male $=0$, female $=1$ ); education $($ no $=0$, yes $=1$ ); marita status (single $=0$, marriage $=1)$; income $(600-999=0,1000-4999=1, \geq 5000=2)$; ethnic ( Tai Hmong; no $=0$, yes $=I$, Lua; no $=0$, yes $=I$, Karens; no $=0$, yes $=I$, Tai Lue; no $=0$, yes $=\mathrm{I})$, incurrent disease $(\mathrm{HT} ;$ no $=0$, yes $=\mathrm{I}, \mathrm{DM} ;$ no $=0$, yes $=\mathrm{I}$, other diseases; no $=$ 0 , yes $=1)$; alcohol intake $($ no $=0$, yes $=1)$; smoking $($ no $=0$, yes $=1)$; age, self-care behaviors, and quality of life $=$ continuous data. *Significant $\mathrm{p}$-value.

believe that the food and alcohol will help cure illness. The people believe they are sick because they have done something wrong to the spirit nature and the spirits bring curses to their family or village members. ${ }^{21}$
Factors associated with self-care behaviors among the elderly from ethnic minority groups were social and cultural factors that include herbal medicine, traditional healing, worshiping nature spirit, and buying medicine from a local drugstore without a prescription. In addition, the learning process of self-care behaviors among ethnic minority groups comes from ancestors using past experience related to the culture, tradition, beliefs, and rituals. This is in accordance with the report from the Department of Health, Ministry of Public Health Thailand, which stated that self-care behaviors among the highland ethnic group such as Lua and Karens are low, which can be seen in the high rate of cigarette smoking and alcohol drinking; these behaviors can be explained through familiar lifestyle and ignorance of the consequences of one's actions. ${ }^{5,20}$ A previous study showed that the self-care behaviors of the Sgaw Karens were at a moderate level, including six areas of health-promoting behaviors: spiritual development, interpersonal relationship, nutrition, exercise, health care behaviours, and stress management. These areas are interrelated with the culture and tradition among the ethnic groups. $^{22}$

Each aspect of universal self-care requisites is at a moderate level, including personal hygiene, bathing, and hair washing, which is consistent with the Akha ethnic group living in the Chiang Rai province. ${ }^{20}$ These people believe that washing the body once a day will help them to be healthy and not to get sick easily. In general, they usually do not clean their teeth. This is because they prefer

Table 4 Self-Care Behaviors Related to the Quality of Life Among Elderly Minority Groups by Multiple Linear Regression

\begin{tabular}{|c|c|c|c|c|c|}
\hline Variables & B & SE & Beta & p-value & $95 \% \mathrm{Cl}$ \\
\hline (Constant) & 64.81 & 4.28 & & $<0.001 *$ & $56.4 I, 73.2 I$ \\
\hline Age (years) & -0.69 & 0.04 & -0.402 & $<0.00 I^{*}$ & $-0.78,-0.60$ \\
\hline \multicolumn{6}{|l|}{ Ethnic } \\
\hline Tai Hmong & Ref. & & & & \\
\hline Lua & 4.84 & 0.88 & 0.184 & $<0.001 *$ & $3.10,6.57$ \\
\hline Karens & 3.47 & 0.95 & 0.123 & $<0.001 *$ & $\mathrm{I} .6 \mathrm{I}, 5.33$ \\
\hline Tai Lue & 1.76 & 0.93 & 0.061 & 0.059 & $-0.06,3.59$ \\
\hline \multicolumn{6}{|l|}{ Incurrent disease } \\
\hline No & Ref. & & & & \\
\hline HT & -2.03 & 0.78 & -0.073 & $0.009 *$ & $-3.92,-1.26$ \\
\hline DM & -5.35 & 0.90 & -0.164 & $<0.001 *$ & $-3.55,-0.50$ \\
\hline Other diseases & -1.72 & 1.07 & -0.045 & 0.107 & $-7.12,-3.59$ \\
\hline Smoking & -2.59 & 0.68 & -0.100 & $<0.00 I^{*}$ & $-3.82,0.37$ \\
\hline Self-care behaviors (scores) & 0.30 & 0.02 & 0.474 & $<0.00 I^{*}$ & $0.27,0.33$ \\
\hline
\end{tabular}

Note: *Significant p-value. 
Table 5 Relationship Between Self-Care Behaviors and the Quality of Life of Each Elderly Minority Group by Multiple Linear Regression

\begin{tabular}{|c|c|c|c|c|c|c|}
\hline Ethnic & Variables & B & Se. & Beta & p-value & $95 \% \mathrm{Cl}$ \\
\hline \multirow[t]{8}{*}{ Lua } & (Constant) & 66.85 & 8.26 & & $<0.00 I^{*}$ & $50.58,83.11$ \\
\hline & Age (years) & -0.80 & 0.09 & -0.414 & $<0.001 *$ & $-0.97,-0.62$ \\
\hline & Incurrent disease & & & & & \\
\hline & No & Ref. & & & & \\
\hline & $\mathrm{HT}$ & -2.29 & 1.65 & -0.069 & 0.168 & $-5.54,0.97$ \\
\hline & DM & -6.12 & 1.71 & -0.177 & $<0.00 I^{*}$ & $-9.49,-2.75$ \\
\hline & Other diseases & -4.35 & 2.04 & -0.104 & $0.034^{*}$ & $-8.36,-0.33$ \\
\hline & Self-care behaviors (scores) & 0.37 & 0.03 & 0.499 & $<0.00 I^{*}$ & $0.30,0.43$ \\
\hline \multirow[t]{8}{*}{ Karens } & (Constant) & 67.65 & 6.53 & & $<0.00 I^{*}$ & $54.78,80.52$ \\
\hline & Age (years) & -0.59 & 0.07 & -0.404 & $<0.001 *$ & $-0.73,-0.44$ \\
\hline & Incurrent disease & & & & & \\
\hline & No & Ref. & & & & \\
\hline & $\mathrm{HT}$ & -2.81 & 1.40 & -0.110 & $0.046 *$ & $-5.56,-0.05$ \\
\hline & DM & -7.08 & 1.30 & -0.296 & $<0.00 I^{*}$ & $-9.64,-4.52$ \\
\hline & Other diseases & -3.32 & 1.51 & -0.121 & $0.029 *$ & $-6.30,-0.35$ \\
\hline & Self-care behaviors (scores) & 0.25 & 0.03 & 0.474 & $<0.00 I^{*}$ & $0.20,0.31$ \\
\hline \multirow[t]{10}{*}{ Tai Lue } & (Constant) & 66.58 & 9.80 & & $<0.00 I^{*}$ & $47.24,85.91$ \\
\hline & Age (years) & -0.69 & 0.10 & -0.380 & $<0.00 I^{*}$ & $-0.89,-0.49$ \\
\hline & Education & -3.40 & 1.46 & -0.129 & $0.021 *$ & $-6.28,-0.51$ \\
\hline & Incurrent disease & & & & & \\
\hline & No & Ref. & & & & \\
\hline & $\mathrm{HT}$ & 0.22 & 1.63 & 0.008 & 0.895 & $-3.01,3.44$ \\
\hline & DM & -4.48 & 2.05 & -0.125 & $0.030 *$ & $-8.53,-0.43$ \\
\hline & Other diseases & 0.49 & 2.53 & 0.011 & 0.846 & $-4.50,5.48$ \\
\hline & Smoking & -4.31 & 1.44 & -0.166 & $0.003 *$ & $-7.15,-1.47$ \\
\hline & Self-care behaviors (scores) & 0.30 & 0.04 & 0.510 & $<0.001 *$ & $0.23,0.37$ \\
\hline \multirow[t]{8}{*}{ Tai Hmong } & (Constant) & 66.27 & 8.71 & & $<0.00 I^{*}$ & $49.08,83.46$ \\
\hline & Age (years) & -0.68 & 0.09 & -0.443 & $<0.00 I^{*}$ & $-0.85,-0.50$ \\
\hline & Incurrent disease & & & & & \\
\hline & No & Ref. & & & & \\
\hline & HT & -4.64 & 1.45 & -0.191 & $0.002 *$ & $-7.50,-1.78$ \\
\hline & DM & -2.20 & 2.48 & -0.052 & 0.375 & $-7.09,2.69$ \\
\hline & Other diseases & -0.38 & 2.82 & -0.008 & 0.892 & $-5.95,5.18$ \\
\hline & Self-care behaviors (scores) & 0.28 & 0.04 & 0.438 & $<0.00 I^{*}$ & $0.21,0.36$ \\
\hline
\end{tabular}

Note: *Significant p-value.

to chew betel nut instead of brushing teeth; according to their belief, chewing betel nut helps clean the teeth and mouth.

In terms of health deviation self-care requisite, it was found that the elderly from all ethnic groups have the same basic beliefs about health and self-care. When illness occurs, they exercise the same treatment methods based on beliefs, tradition, and culture. They usually cure themselves by taking medicine first, and then use herbal treatment. If the illness remains, they tend to seek treatment from a local spiritual healer to perform rituals such as worshiping. Only a few elders would seek treatment at a hospital or health service unit. Although there is a policy for the elderly to access health service based on their rights, some problems still exist. For instance, first, they do not know about their rights to health. Secondly, they are living in a remote area in which it is inconvenient to commute, and finally, they have financial problems that 
prevent healthcare and travel. This study is similar to the previous studies. It was mentioned that ethnic people retain their ways of traditional treatment such as performing rituals or using herbal treatments. ${ }^{3}$ A study found that some elderly people may not receive quality health care because they have no relatives or caregivers to provide help for them. In some situations, family caregivers do not have enough time to support the family and do not have enough money for transportation and other expenses. ${ }^{23}$ Another study found that some elderly people living with chronic diseases do not undergo health screenings for hypertension and diabetes provided by the health center, because they do not know about their rights to health and have some financial restrictions that make travelling and paying for medical expenses difficult. ${ }^{24}$

The quality of life among the elderly is found to be at a moderate level. This can be explained by the fact that, as age increases, more physical limitations arise in doing daily activities. This is consistent with the health theory. ${ }^{25}$ The perception of health is linked to illness. There are also associations between health experience and education. When people age, their physical and mental functions are reduced. They begin to rely more heavily on others to help with daily and social activities, which in turn may reduce their overall quality of life. ${ }^{18}$ This is similar to the study which mentioned that quality of life among elderly people is at a moderate level due to the change in the community context from rural to semi-urban society and community expansion. With the expansion of urban areas, the government established policies to support financial assistance to protect the elderly, thus leading to a better quality of life. ${ }^{18,26}$

The important variables that affect the quality of life include age, ethnicity, smoking, congenital disease, and self-care behaviors. Even alcohol consumption became non-significant when adjusted by other variables; it was associated with the quality of life in bivariate regression analysis. This is consistent with a study that stated that drinking alcohol is a predicting factor of quality of life among the elderly people within a community. ${ }^{17}$ Age was inversely related to the quality of life, because health functions gradually changed over time, causing deterioration of various organs and resulting in health problems and decreased the performance of daily activities. ${ }^{18}$ There is a change in the health of the elderly that is linked to their body, mind, and society. Their ability to perform activities and social roles decreases, and they have to rely more heavily on others. ${ }^{27}$ Furthermore, physical deterioration can cause health problems and chronic diseases. Chronic conditions, especially hypertension and diabetes, are negatively associated with quality of life among the elderly from ethnic minority groups. The influence of smoking also could significantly decrease the quality of life. In addition, the current study found a high percentage of elderly minority smokers, which leads to many health problems. A previous study found that elderly people smoke 1-5 cigarettes a day, and most smoke a half pack a day, and almost $80 \%$ are affected by health problems, especially chronic non-communicable diseases. ${ }^{28}$ In addition to smoking behavior, agriculture entities burn down the forest land, and air pollution from farming may affect their health. ${ }^{21}$

This research found an association between ethnic groups and quality of life among the elderly. Each ethnic group has a different context and lifestyle and cultural beliefs as mentioned above. This is consistent with prior studies, ${ }^{3}$ which found that the quality of life among the ethnic elderly in Chiang Rai province is different from the elderly living in other rural communities due to the perception of the people under tradition and beliefs. Ethnic groups' identities are shown through traditions and various beliefs and are related to the quality of life among them.

Self-care behaviors were positively related to the quality of life among minority elders, even if the ethnic groups were separately divided and analyzed to show a rather strong correlation (beta $=0.438-0.510$ ). Those who demonstrate good self-care behaviors, including universal, developmental, and health deviation self-care requisites tend to pay closer attention to their health care and improve their quality of life. In addition, the current study found the lowest score of self-care behaviors among the ethic group of Karens, similar to the report of ethnic group studies that self-care behaviors among ethnic people such as Lua and Karens were at low levels. ${ }^{21}$ This finding can be explained by the fact that these people's self-care behaviours are based on their beliefs and traditions. They have a ritual of healing sickness by worshiping the sacred. The majority of elders go to the pharmacy first and do not like to visit the hospital until their health conditions become worse. ${ }^{3}$ If they perform better selfcare behaviors, they have better health, and better health and well-being can lead to a higher quality of life. Other studies confirm the strong associated relationship between illness and quality of life among elderly people..$^{17,27,29}$ 


\section{Limitations and Recommendations}

There are several limitations to this study. First, since this is a self-report, there may be some misinformation regarding health history among the participants. However, the researcher took efforts to ensure that the obtained information is accurate, and the elderly people were diagnosed and their health was re-checked at a health service center. Second, elders aged 80 years and older were excluded from the study due to communication problems during the interview. However, the results of this research were obtained from people within the age range of 60-79 years of age. Most elderly people who participated in the study used mainly northern dialects. There was no written language used in the study. The research team had to use local language while conducting face-to-face conversations with the ethnic participants. There may have been some misunderstandings, and the obtained information may not be comprehensive. Therefore, the researcher and the team had to be trained in order to engage in communication and obtain information from the elderly.

\section{Conclusion}

In conclusion, there is a relationship between self-care behaviors and quality of life among elderly minority groups along the border of Thailand. The differences in background, traditions, and cultures could impact the quality of life. However, government and health-related agencies should provide health care awareness regarding factors affecting their health and well-being within the context of tradition, cultures, and beliefs for particular groups of people to enhance their experience and skills related to health. Health agencies should raise awareness and thus promote the development of healthy behaviors among people of ethnic groups. In addition, local government organizations from the provincial public health office should create a policy or a project plan to promote and to enhance the quality of life of the elderly from ethnic minority groups in a clear and holistic way. Such an action can be accomplished by providing social welfare for these people. In the future, additional studies should focus on chronic diseases associated with lifestyle behaviors of each ethnic group and the factors that promote health. Qualitative research should be done in order to gain a deeper insight into how to develop and promote health and self-care behaviors with consideration for cultural differences. Such an understanding will help increase the quality of life among various ethnic groups.

\section{Acknowledgments}

The authors would like to extend their sincere appreciation to the University of Phayao (Grant No. RD62049) for the financial support of this research. The authors also express their deepest gratitude to all participants for their contribution to the study.

\section{Disclosure}

The authors report no conflicts of interest in this work.

\section{References}

1. Arifin EN. Growing old in Asia: declining labour supply, living arrangements and active ageing. Asia Pac Popul J. 2006;21(3):17-30. doi:10.18356/06d1229d-en

2. Department of Older Persons. Statistics, Number Separated by Province, and Age: 2018. Bangkok, Thailand: Ministry of Social Development and Human Security. Available from: http://www.dop. go.th/th/know/1/159. Accessed April 10, 2019.

3. Tasuwanin T, Maneerat W, Rappakit K, Laorinthong A, Winyangkul P. Quality of life of the elderly ethnic in Chiang Rai Province. J Nurs Health Care. 2018;36(4):74-82.

4. Phongsapich A. Society and Culture. Bangkok, Thailand: Chulalongkorn University Press; 2004

5. Health Center of Ethnic group, Migrant Peoples and Migrant Workers. Health Promotion and Environmental Management of the Lua Hill Tribe People. Thailand: Department of Health Ministry of Public Health; 2015. Available from: http://hhdc.anamai.moph.go.th/data base/admin/research/file/200814102014.pdf. Accessed April 10, 2019.

6. World Health Organization. World Report on Ageing and Health. Geneva, Switzerland: World Health Organization; 2015.

7. Bureau of Non-Communicable Diseases. Number and death rate of non-communicable diseases 2016 - 2017. Available from: http:// www.thaincd.com $/ 2016 / \mathrm{mission} /$ documents-detail.php?id= 13486\&tid=32\&gid=1-020. Accessed April 10, 2019.

8. Boult C, Green AF, Boult LB, Pacala JT, Snyder C, Leff B. Successful models of comprehensive care for older adults with chronic conditions: evidence for the Institute of Medicine's "Retooling for an aging America" report. J Am Geriatr So. 2009;57:2328-2337. doi:10.1111/ j.1532-5415.2009.02571.x

9. World Health Organization. Programme on Mental Health: WHOQOL Measuring Quality of Life. Geneva: WHO; 1997.

10. Orem DE. Nursing Concepts of Practice. New York: McGraw-Hill Book; 1985.

11. World Health Organization. WHO-Qol Old Manual. Copenhagen: WHO European office; 2004.

12. Power M, Quinn K, Schmidt S. Development of the WHOQOL-Old module. Qual Life Res. 2005;14(10):2197-2214. doi:10.1007/s11136005-7380-9

13. Cochran WG. Sampling Techniques. New York: John Wiley \& Sons. Inc. Book; 1977.

14. Kerlinger FN, Pedhazur EJ. Multiple Regression in Behavioral Research. New York: Holt, Rinchart and Winston; 1973.

15. Booranaklas W. The correlation between the self-care behaviors, family relationship and happiness of the elderly at the community Saimai district in Bangkok metropolitan. JOPN. 2017;9(2):24-32.

16. SaengngernNar S, Noosorn O, Maton T, Wanaratwichit C. Factors predicting individual health promoting behaviors in older people living alone. J Public Health. 2012;42(2):68-81.

17. Hongthong D, Somrongthong R, Ward P. Factors influencing the Quality of Life (Qol) among Thai older people in a rural area of Thailand. Iran J Public Health. 2015;44(4):479-485. 
18. Jiandon C, Suwannapong N, Boonshuyar C, Howteerakul N. Quality of life of rural elderly in Wangnamkheaw District, Nakhonratchasima Province. J Public Health. 2011;41(3):229-239.

19. Liu MH, Wang CH, Huang YY, Cherng WJ, Wang KW. A correlational study of illness knowledge self-care behaviors and quality of life in elderly patients with heart failure. J Nurs Res. 2014;22(2):136-144. doi:10.1097/JNR.0000000000000024

20. Manotham M, Koychusakun P, Choyae A, Maneerat W, Muangmool J, Vanishprinyakul S. Knowledge and behaviors for healthcare of Akha ethnic group in Mae Suai District, Chiang Rai Province, Thailand. Public Health J Burapha Univ. 2019;14(1):69-80.

21. Department of Social Development and Welfare. Highland Communities Within 20 Provinces of Thailand 2002. Bangkok, Thailand: Ministry of Social Development and Human Security. Available from: http://hhdc.anamai.moph.go.th/ewt_dl_link.php?nid= 1707\&filename=download. Accessed April 20, 2019.

22. Mahathamnuchock S. Health promotion behaviors of Sgaw Karens in risk of Non-Communicable Disease (NCD). Nurs J (Manila). 2015;42(Supplement):118-125.

23. Wirojratana V, Amnatsatsue K, Sasat S, Malathum P, Narongsak J. Improvement of healthcare services for dependent elders. Thai J Nurs Council. 2014;29(3):104-115.
24. Booranarek S, Thummaraksa P, Kaewchuntra K, Khamwong M. Health status and health service accessibility: Samsen community. J Boromarajonani Coll Nurs Bangkok. 2017;33(2):54-63.

25. Pender NJ. Health Promotion in Nursing Practice. 2nd ed. Stamford, CT: Appleton \& Lange; 1987.

26. Khaje-Bishak Y, Payahoo L, Pourghasem B, Asghari Jafarabadi M. Assessing the quality of life in elderly people and related factors in Tabriz, Iran. J Caring Sci. 2014;3(4):257-263. doi:10.5681/ jes.2014.028

27. Pradeep GC, Tiraphat S, Chompikul J. Factors associated with quality of life among the elderly in Baglung District Nepal. J Public Health Dev. 2017;13(3):51-64.

28. Somrongthong R, Hongthong D, Wongchalee S, Wongtongkam N. The influence of chronic illness and lifestyle behaviors on quality of life among older Thais. Biomed Res Int. 2016;2016(2525941):1-7. doi:10.1155/2016/2525941

29. Vathesatogkit P, Sritara P, Kimman M, et al. Associations of lifestyle factors, disease history and awareness with health-related quality of life in a Thai population. PLoS ONE. 2012;7(11):1-9. doi:10.1371/ journal.pone.0049921
Journal of Multidisciplinary Healthcare

\section{Publish your work in this journal}

The Journal of Multidisciplinary Healthcare is an international, peerreviewed open-access journal that aims to represent and publish research in healthcare areas delivered by practitioners of different disciplines. This includes studies and reviews conducted by multidisciplinary teams as well as research which evaluates the results or conduct of such teams or healthcare processes in general. The journal

\section{Dovepress}

covers a very wide range of areas and welcomes submissions from practitioners at all levels, from all over the world. The manuscript management system is completely online and includes a very quick and fair peer-review system. Visit http://www.dovepress.com/testimonials. php to read real quotes from published authors. 